\title{
AGILE PROJECT MANAGEMENT APPROACH, METHODS AND ITS APPLICATION IN GEORGIA
}

\section{NINO GORGADZE}

\author{
Associate Professor \\ European University, \\ PhD student, \\ Ivane Javakhishvili Tbilisi State University, Georgia \\ ninogorgadze@gmail.com
}

\begin{abstract}
The article discusses the relatively modern Agile approach to project management, its difference from the traditional Waterfall approach, Agile application area, history and principles, advantages and difficulties of implementation and its use. Article discusses the most popular Agile methods (Scram, Kanban, Scramban), global statistics of the most frequently used relevant management software, and the role of Artificial Intelligence (AI) in project management; Changes resulting from the impact of the COVID 19 pandemic, which affected approaches, hybridization of approaches, methods and technologies used. The article is based on global and Georgian market research. The article includes research conducted in Georgia by the author of the article, among seventy relevant specialists from up to sixty organizations. The study outlines the scope and areas of the agile approach, the most commonly used methods and software.
\end{abstract}

KEYWORDS: PROJECT MANAGEMENT, AGILE PROJECT MANAGEMENT, SCRUM, KANBAN, PROJECT MANAGEMENT SOFTWARE, ARTIFICIAL INTELLIGENCE IN PROJECT MANAGEMENT.

For citation: Gorgadze, N., (2021). Agile Project Management Approach, Methods and its Application in Georgia. Globalization and Business. 12, 191-196. https://doi.org/10.35945/gb.2021.12.027

\section{INTRODUCTION}

In the practice of project management, with the introduction of innovative and IT/Software Development projects, in the early 2000 s so-called Agile approach was introduced. The official beginning of the Agile approach is considered with the publication of "Agile Manifesto" in 2001. Since the dissemination of the approach, many methods of its use have been developed and implemented (Scrum, Kanban, XP, etc.), as well as a number of softwares for Agile project management; The use of artificial intelligence has also begun to spread widely. The method proved to be so convenient that it is growing within IT sector itself and in another spheres too. Agile approache is already being introduced not only at the project level, but also at the organizational level, not only in the field of information technology but also in marketing, consulting business, education, banking and finance, and even in construction. The COVID 19 pandemic has also increased the level of application of Agile approach and technologies.

According to the Cambridge Dictionary, the word Agile means: "able to move your body quickly and easily (Cambridge Dictionary, 2021). The word Agile is derived from the Latin - agere - "action", refers to the feeling of ownership and the ability to advance something.

In the modern business world, Agile has three charac- teristics that are important for project management: Sense of ownership and authority; Quick and easy change of direction and Convenience and adaptability (Griffin \& Roldan, 2013).

To discuss in more detail, Agile Methods and Methodologies could be considered as a kind of umbrella term that encompasses many methods and models (Project Management Institute 2017), and Agile management is a combination of methods and methodologies that help teams think more efficiently, work more efectively, and make better decisions (The Projex Academy. 2017).

Is Agile an approach, a method, a technique or a framework? All definitions are acceptable and correct, depending on the area of application (Project Management Institute, 2017). In this article, we call Agile the approach, as we discuss what it means in a broad sense.

However, globally almost all authors agree that Agile is a more mindset (The Projex Academy, 2017) based on the exchange of information between project team members, assistance in information retention and joint decision making, and not just whole cycle management by the project manager as is in the Waterfall approach.

According to one of the surveys conducted in the field of IT and Software Development, $67 \%$ of organizations work with Agile, $24 \%$ with hybrid and $9 \%$ with Waterfall approaches (techbeacon.com, 2015). 


\section{HISTORY AND PRINCIPLES}

The first signs of the Agile approach appeared in the 1980s, when small multidisciplinary teams integrated into Toyota Lean production system increased customer satisfaction and quality via generating small efficient systems and eliminating unnecessary ones (Gouveia, 2015). Then the Kanban method was developed (Milliken, 1987) and only in 2001 did Agile officially appear on the global stage (Hrablik et al., 2020), because with the Waterfall become problematic to manage projects in the IT field. In 2001 The "Agile Manifesto" was published, outlining the four values of Agile and the twelve basic principles (which are detailing four values) (Hrablik et al., 2020).

Four values of Agile: "1. Individuals and interactions over processes and tools; 2 . Working software over comprehensive documentation; 3 . Customer collaboration over contract negotiation and 4 . Responding to change over following a plan". (Agilemanifesto.org, 2001)

\section{AGILE METHODS}

As was already mentioned above, the Agile approach is most commonly used in the IT and software development fields, although it has successfully established itself in other areas as well, even at the top management level of organizations.

Today, about twenty Agile methods are known (Rasnacis \& Berzisa 2017), which are used for different purposes, have different specifics and the frequency of their use is also different.

The most commonly used Agile methods are the following:

Table 1. Use of Agile Methods, Global and Georgian Statistics, with 2021 data

\begin{tabular}{|c|l|c|c|}
\hline$\#$ & Agile Method & $\begin{array}{c}\% \text { of } \\
\text { application } \\
\text { (global) }\end{array}$ & $\begin{array}{c}\% \text { of } \\
\text { application } \\
\text { (Georgia) }\end{array}$ \\
\hline 1. & Scrum & $66 \%$ & $79,7 \%$ \\
\hline & Scrumban & $9 \%$ & - \\
\hline & Kanban & $6 \%$ & $37,3 \%$ \\
\hline & Scrum/XP & $6 \%$ & - \\
\hline & Iterative & $4 \%$ & - \\
\hline & XP & $1 \%$ & $3,4 \%$ \\
\hline & Lean & $1 \%$ & $8,5 \%$ \\
\hline & Other/non & $6 \%$ & $1,7 \%$ \\
\hline
\end{tabular}

Source: digital.ai. 2021, Stellman. 2016, Author's research

* The research was conducted by the author, in June-September 2021, across Georgia, 70 specialists from up to 60 organizations were interviewed.
According to a survey conducted by the author of the article in Georgia in June-September 2021, in which about 70 professionals participated, $18.6 \%$ manage projects using the Waterfall approach, $32.9 \%$ use the Agile approach, and $48.6 \%$ use the hybrid of both approaches. Statistics are not in doubt as $62.3 \%$ of respondents manage IT projects.

Let's take a closer look at some of the most commonly used methods.

\section{Scrum}

As a result of the 2021 survey, the majority of companies (66\% globally and $80 \%$ in Georgia) use the Scrum method.

Scrum is a lightweight framework that helps people, teams, and organizations create value through adaptive solutions to complex problems. In short, Scrum requires a Scrum Master to help create an environment where (Hrablik et al., 2020):

1. The product owner orders the work needed to solve a complex problem and it is placed in the product backlog.

2. The Scrum team turns part of the work to be done into a value increment during the sprint.

3. Scrum team and stakeholders check the results and prepare for the next sprint.

Figure 1 shows the Scrum framework.

Scrum is used to manage and monitor IT and software development projects efficiently and without problems over a period of time. The Scrum takes place in iterations that cover the same period of time (2-4 weeks). There are several iterations in each project. These iterations in Scrum are called sprints (Hrablik et al., 2020). The Scrum framework consists of events, artefacts, and team roles.

Scrum activities include: Sprint, Sprint Planning, Daily Scrum, Sprint Review, Sprint Retrospective.

Scrum artefacts (represent work or value): Product backlog, Sprint backlog, increment.

Scrum roles are: Scrum team is a small group of people consisting of one Scrum master, one product owner and one or several developers. There are no subgroups and hierarchies in the team and it is self-organizing (Schwaber \& Sutherland, 2020).

As we can see, the Scrum is quite framed and standardized method and although it is also effective in managing large projects since the amount of iterations is not limited (Hrablik et al., 2020).

\section{Kanban}

Kanban is also an Agile method, but partly. Kanban is part of the Agile because it also follows lean concept, which includes a focus on values, small parts management, and elimination of waste (Project Management Institute, 2017).

The Kanban method was introduced in Toyota by Taiichi Ohno to increase production efficiency. Kanban focuses on the continuous delivery of the product or part of it (EyLean. 
Figure 1. Scrum framework

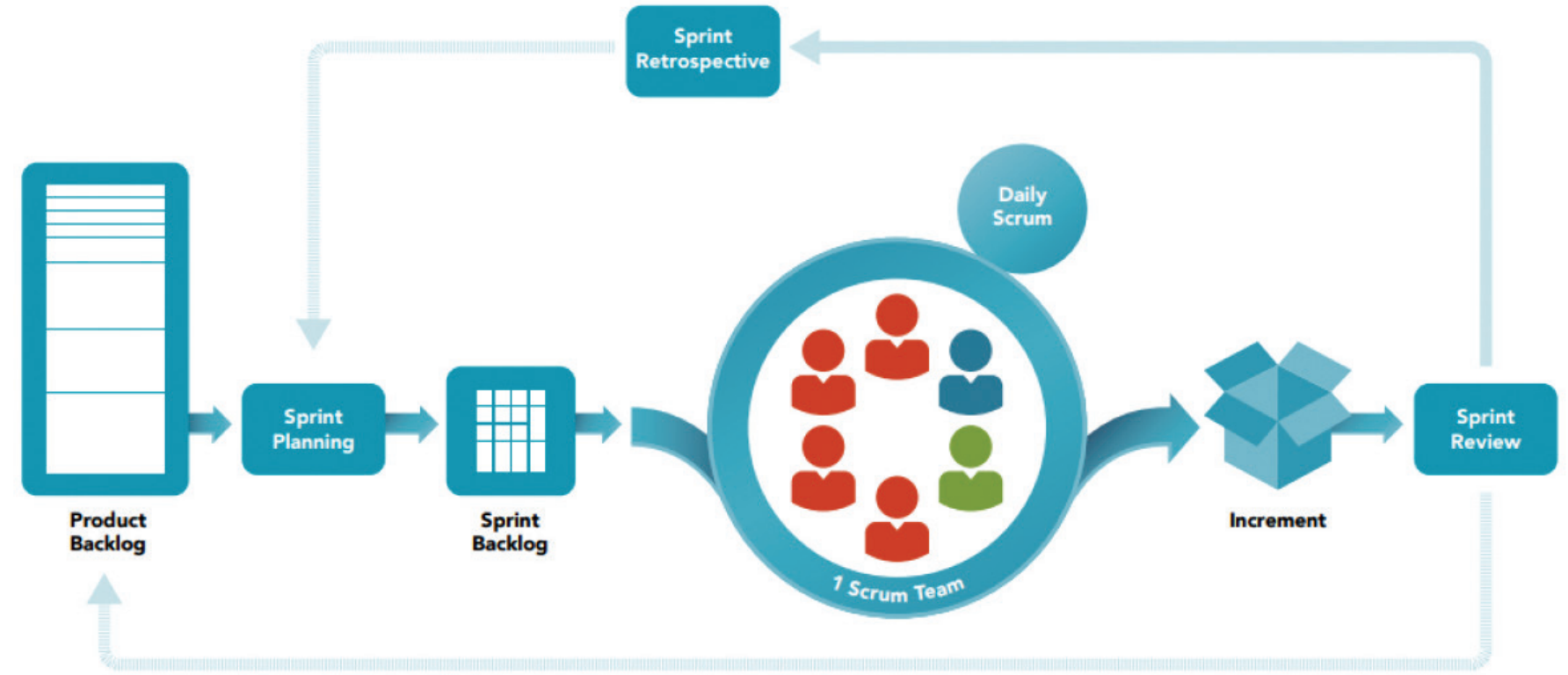

Source: Scrum.org. 2021

com, 2013). A key component of Kanban is the Work in Progress (WIP) Limits, which limit the number of tasks over the same period of time. The main tool of the Kanban is the Kanban board on which the tasks are visualized and moved in columns which reflect process stages (Atlassian.com, 2020). The board remains unchanged, and the tasks placed on it move from the logical beginning to the logical end, and then disappear from the board.

Kanban and Kanban boards, in addition to projects, are widely used in many fields today. For task management at the individual and organizational levels, using a variety of software such as Trello, JIRA, Asana and others (Wrike.com, 2020)

There are important differences between Kanban and Scrum, namely:
- Scrum sprint has start and end dates, Kanban is an ongoing process;

- We have formal roles in Scrum, not in Kanban. Both teams are self-organizing;

- Kanban Board is used for the entire life cycle of the project, while Scrum Board is used for individual sprints;

- Scrum Board has a predefined amount of tasks with its deadlines;

- Kanban boards are more flexible in terms of the amount of tasks and deadlines. Their re-prioritization, change of members and deadlines is painless (Atlassian.com, 2020).

Figure 2. Kanban board

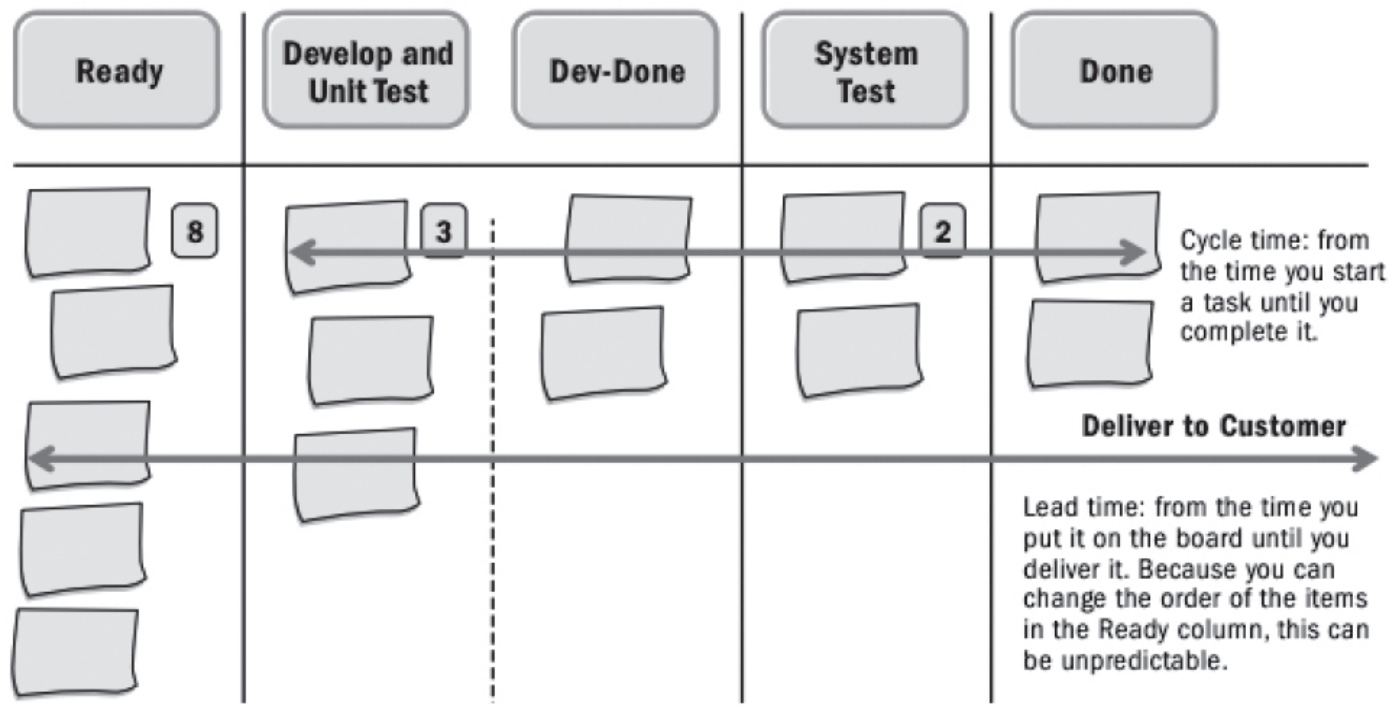

Source: Project Management Institute. 2017 


\section{Scrumban}

The term Scrumban was introduced by Corey Ladas, and expresses the combination of the use of Scrum and Kanban - the basic functions of Scrum and the flexibility of Kanban. Scrumban has a planning-on-demand principle for backlogs, but the tasks are given to performers on a "pool" basis, as in Kanban. Like Kanban, the board is constant here, only the task moves from the beginning to the end, and their priority changes over time, and the planning is done on demand bases and not on every sprint, as in the Scrum. Here, too, boards are used to visualize the tasks (EyLean.com, 2013).

Planning meetings are held to determine which user stories should be implemented during the next iteration. User stories are placed on the board, and team members perform them. The amount of tasks are limited and their completion is a trigger for a new planning. There are no specially defined roles here, team members retain existing roles (Reddy, 2016).

\section{Which method is better?}

It is difficult to say exactly which approach or method is better. On the one hand, the Waterfall method is more appropriate when there is less uncertainty in the project, goals and objectives are clear and well defined at the beginning. On the other hand, Agile is better when there is a lot of uncertainty and changes in the project, it is innovative and creative because Agile is much more flexible (Schwaber \& Sutherland, 2020).

The PMI 2021 Pulse of the Profession ${ }^{\circledR}$ study identified so-called Gymnastic Enterprises for the first time. These organizations and their project teams are characterized by a high level of flexibility and maneuverability. Old-fashioned organizations were called Traditional Enterprises, regardless of the approach they took - Waterfall or Agile. The most important difference between Gymnastic Enterprises and Traditional ones is that they use all the approaches / methods and their combinations according to the needs and challenges and do not use any of the established methods rigidly (Project Management Institute, 2021)

Gymnastic Enterprises make a lot of changes compared to Traditional ones: digital transformation (Gymnastic 73\%, Traditional 62\%), business strategy (Gymnastic 70\%, Traditional 57\%), organizational adaptability (Gymnastic 70\%, Traditional 53\%), operational efficiency (Gymnastic 65\%, Traditional 52\%), innovation (Gymnastic 65\%, Traditional 46\%) and other components. Gymnastic Enterprises also deliver much better results in terms of project delivery (Project Management Institute, 2021).

Consequently, we can say that situational mix of approaches and methods yields much better results than the use of any one method strictly.

\section{Difficulties in the introduction of Agile}

Recent studies have shown that Agile is a fairly effective method in a number of areas compared to the Waterfall method. The success rate of Agile projects is high, as can be seen in Table 2.
Table 2. Comparison of Agile and Waterfall approaches

\begin{tabular}{|c|c|c|c|}
\hline Approach & Success & Problematic & Failed \\
\hline Agile & $42 \%$ & $50 \%$ & $8 \%$ \\
\hline Waterfall & $26 \%$ & $53 \%$ & $21 \%$ \\
\hline
\end{tabular}

Source: vitilitychicago.com, 2019

Despite the effectiveness, there are a number of difficulties with the introduction of Agile. According to the 15th State of Agile 2021 survey, 30\% of respondents named at least ten problems as a barrier to implementation and the main from them are: (digital.ai, 2021)

- Inconsistency in processes and practice $46 \%$;

- Cultural incompatibility $43 \%$;

- General organizational resistance to change $42 \%$;

- Lack of skills and experience $42 \%$;

- $\quad$ Lack of leadership 41\%;

- Inadequate management support $40 \%$.

Despite these barriers, Agile has many positive effects, in particular fast management of changing priorities, increased transparency, effective business and IT alignment, market launch speed, increased team productivity - survey respondents mentioned these points as the most important positive effects of Agile (70-60\%) (digital.ai, 2021).

\section{Technologies in project management}

Today, project management, especially Agile management, is fully or almost completely implemented through various professional software. The COVID 19 pandemic in particular has accelerated the digitization process as humans have moved to remote working mode and still partially maintain this trend. For example, the biggest change in 2020-2021 is the digital transformation, which accounts for $68 \%$ of the changes. (Project Management Institute, 2021). According to the 15th State of Agile Report (2021) globally most commonly used software is Jira (digital.ai, 2021), which also leads in Georgia (author's research), followed by Digital.ai, Azure DevOps, Broadcom, and Trello. According to the author's research in Georgia, the picture is partially different from the global data, namely: in Georgia, as well as globally, the program JIRA is the most popular, while Microsoft Project is much more popular in Georgia, including IT projects, and Azure DevOps is now gaining ground; some globally popular programs are not used at all in Georgia.

\section{Artificial Intelligence (AI) in project management}

Al is already used for administrative tasks such as registering and logging, automating appointments, including booking rooms, sending invitations by email, and more. It gradually evolves into project management and over existing more complex tasks (rpsgroup.com, 2021).

The main reasons for introducing artificial intelligence in project management are: improved decision making, 
Table 3. The most commonly used software in project management, global and Georgian data.

\begin{tabular}{|c|l|c|c|}
\hline$\#^{*}$ & Software (Toolling) & \% of application (global) & \% of application (Georgia)* \\
\hline 1 & Atlassian Jira & $81 \%$ & $51,5 \%$ \\
\hline 2 & Digital.ai & $70 \%$ & - \\
\hline 3 & Azure Devops & $66 \%$ & $1,4 \%$ \\
\hline 4 & Broadcom Rally & $62 \%$ & - \\
\hline 5 & Trello & $59 \%$ & $31,4 \%$ \\
\hline 7 & Google Docs & $48 \%$ & $1,4 \%$ \\
\hline 13 & MS Project & $35 \%$ & $32,9 \%$ \\
\hline 15 & MS office (excel, doc) & $32 \%$ & $42,9 \%$ \\
\hline- & Microsoft 365 (teams, planner) & - & $20 \%$ \\
\hline- & Asana and Miro & - & $22,8 \%$ \\
\hline
\end{tabular}

Source: digital.ai, 2021, Author's research

increased productivity levels, better performance and reporting. It is now considered that Machine Learning has the greatest potential in Al technologies in terms of application in project management.

As for the various artificial intelligence technologies used in the projects, although currently only $4 \%$ of companies globally use them extensively, $65 \%$ have already said they are working on an implementation plan or are already planning to start the planning process in the next 3-6 months. The companies plan to introduce artificial intelligence in three main areas: Predictive Analytics Tools, Chat Bots and Robotic Process Automation (RPA) (International Project Management Association, 2020).

According to current forecasts, by 2025 Al will be able to: plan projects, allocate resources, create budgets, assist with contract administration, evaluate cost received, and perform completion cost forecasts (rpsgroup.com, 2021).

\section{About the research conducted by the author in Georgia}

In the period June-August 2021, the author of the article interviewed 70 professionals working in Georgia, from up to 60 organizations that have direct contact with project management.

Table 4 lists the respondents' activities, experiences, and
* Numbering is done according to global statistics project types that they run most frequently. As we can see, the project was mainly attended by project managers with average experience.

The vast majority of respondents are employed in the private sector $(81.4 \%)$, led by banking-finance $(24.3 \%)$ and IT companies (18.6\%). The remaining $18.6 \%$ are employed in public sector.

\section{CONCLUSION}

As we have seen, the Agile approach is still mainly used in the field of IT and software development, although its various elements / principles and software are effectively introduced and developed in many other areas as well. Also in Georgia, private and public organizations working with IT projects are actively using this method and latest software are also used successfully. The tendency is to growing demand of Agile, because we are facing global increases of digitalization and growing degree of turbulence in all areas of economy.

Agile has many positive effects on the organization and the effectiveness of projects, however the first thing an organization needs to understand the reason for Agile application, because incorrectly selected processes and practices, along with team cultural incompatibility, can have quite negative consequences.

Table 4. Positions and experiences of the professionals participating in the study. 2021

\begin{tabular}{|l|c|l|c|}
\hline Position & $\mathbf{\%}$ & Experience & \% \\
\hline Project/ Program / Portfolio manager & 50 & $>2$ years & 21.4 \\
\hline Functional Manager & 36 & $2-5$ years & 45.7 \\
\hline CEO & 14 & 5 years and more & 32.9 \\
\hline
\end{tabular}


Despites there are up to twenty methods of Agile project management, several international standards and more than a dozen software, its use and implementation is still associated with a number of problems. The introduction of the new Agile approach requires first of all appropriate preparation of the team, because resistance to change is very natural condition. Additionally, we should not forget that Agile is a very different management scheme, the team is self-governing, which requires a high level of self-management, motivation and understanding on the part of the project team and leaders. Only then it is appropriate to introduce a specific method, framework, artifacts, software, and identify relevant roles of Agile.

At the expense of the rapid development of technology on the one hand, and the strengthening of the VUCA world on the other, and the impact of the COVID 19 pandemic, situational mix of approaches and methods, utilization of software and artificial intelligence capabilities will be the most effective (and in part already) way for future development in projects management.

\section{REFERENCES:}

Agilemanifesto.org (2001). Agile Basic Principles of the Manifest. Online available at: https://agilemanifesto.org/iso/ka/principles.html_(in Georgian).

Atlassian.com (2020). What is a Kanban Board, Online available at: https://www.atlassian.com/agile/kanban/boards

Cambridge Dictionary (2021). Definition of agile on English. Online available at: https://dictionary.cambridge.org/dictionary/ english/agile

digital.ai (2021). $15^{\text {th }}$ State of Agile Report.

EyLean.com (2013). Scrum vs. Kanban vs. Scrumban.

Gouveia, D.R. (2015). An Essay on Agile Project Management Practices. Universidade Nova de Lisboa, Faculdade de Ciências e Tecnologia.

Griffin, C., \& Roldan, M. (2013). Swimming up the waterfall: agile processes in a waterfall world. Paper presented at PMI ${ }^{\circledR}$ Global Congress (2013) - North America, New Orleans, LA. Newtown Square, PA: Project Management Institute.

Hrablik, H., Husovič, R., Babčanová, D., \& Makyšová, H. (2020). Agile Project Management - What is It?.

International Project Management Association (2020). Artificial Intelligence impact in Project Management.

Milliken, F. (1987). Three Types of Perceived Uncertainty about the Environment: State, Effect, and Response Uncertainty. Academy of Management review. 133-143.

Project Management Institute (2017). Agile Practice Guide.

Project Management Institute (2021). Beyond Agility: Flex to the Future. Pulse of the Profession ${ }^{\circledR}$. online available at: [https:// www.pmi.org/learning/library/beyond-agility-gymnastic-enterprises-12973?fbclid=IwAR24oXduVtqHKYXp62UYitbbjZ1HGv-789abT7LDC_dgRWvYIAys4v1gWpo] Accesses on 01/05/2021.

Rasnacis, A., \& Berzisa S. (2017) Method for Adaptation and Implementation of Agile Project Management Methodology, Procedia Computer Science, 104, 43-50, https://doi.org/10.1016/j.procs.2017.01.055.

Reddy, A. (2016). Scrumban Evolution, The: Getting the Most Out of Agile, Scrum, and Lean Kanban (Agile Software Development Series.

rpsgroup.com. (2021). The Impact of Al on Project Management. Available online at: https://www.rpsgroup.com/insights/ the-impact-of-ai-on-project-management/

Schwaber, K., \& Sutherland J. (2020). The Definitive Guide to Scrum: The Rules of the Game. Available online at: https:// scrumguides.org/docs/scrumguide/v2020/2020-Scrum-Guide-US.pdf\#zoom=100

Scrum.org (2021). The scrum framework Poster. Online available at: https://www.scrum.org/resources/scrum-framework-poster Stellman, A., \& Greene, J. (2016). Learning Agile: understanding scrum, xp, lean and Kanban.

techbeacon.com (2015). Survey: Is agile the new norm?. Available online at: https://techbeacon.com/app-dev-testing/surveyagile-new-norm

The Projex Academy (2017). Agile Methodology and PMBOK - PMP Mastery. Online Available: http://www.pm-primer.com/ agile-methodology-and-pmbok/.

vitilitychicago.com. (2019). Agile Project Success Rates Are 2X Higher Than Traditional Projects. Online Available at: https:// vitalitychicago.com/blog/agile-projects-are-more-successful-traditional-projects/

Wrike.com (2020). The Complete Guide to Personal Kanban. Online Available at: https://www.wrike.com/blog/complete-guide-personal-kanban/ 